Japan. J. Med. Sci. Biol., 32, 1-18, 1979

\title{
IMMUNOTHERAPEUTIC TRIALS OF MURINE AND GUINEA-PIG SOLID TUMORS BY ORAL ADMINISTRATION OF BCG
}

\author{
Tohru TOKUNAGA, Satoru TAGUCHI**, Fumitoshi CHINO* \\ and TоYоно MUROHASHI
}

\begin{abstract}
Department of Tuberculosis, National Institute of Health, 2-10-35, Kamiosaki, Shinagawa-ku, Tokyo 141, and *Department of Pathology, National Institute of Health, Gakuen, Musashimurayama, Tokyo 190-12, Japan
\end{abstract}

(Received: November 15, 1978)

\begin{abstract}
SUMMARY: Efficacy of oral administration of BCG on the growth of various tumors in mice and guinea pigs was studied. The growth-inhibitory effect varied depending on the tumor systems and the experimental conditions. Weekly oral administrations with 5-mg doses of BCG to mice or $80-\mathrm{mg}$ doses of BCG to guinea pigs were ineffective on syngeneic mouse melanoma B16 or syngeneic guinea pig hepatocarcinoma line-10 but effective on syngeneic mouse carcinoma IMC and syngeneic guinea-pig fibrosarcoma H9A. Oral BCG seemed effective also on allogeneic mouse carcinoma Ehrlich, developed with a relatively small size of tumor cell inoculum, and on guinea-pig syngeneic liposarcoma H10. On Ehrlich tumors, oral BCG given once a week seemed to have better effects than did oral BCG given twice a week or subcutanously once or repeatedly; heat-killed BCG given orally showed no effect. However, it seems premature to draw a definite conclusion on the efficacy of oral BCG on Ehrlich and H10 tumors, because some of these tumors regressed spontaneously even in nontreated control animals.

The host responses to oral BCG were studied with the following results. Weekly oral administrations with $80-\mathrm{mg}$ doses of BCG to guinea pigs elicited positive skin reactions to $25 \mathrm{TU}$ PPD in about 65 days after the first BCG, while a single sc injection of $8 \mathrm{mg}$ of BCG did so within 10 days. Orally administered BCG organisms were recovered largely from Peyer's patches, a little from the mesenteric lymph nodes, and very little from the liver and the spleen. The BCG distributive pattern was in reverse order when BCG was given subcutaneously. Histologic examinations of Peyer's patches indicated enlargement of germinal centers, in which primitive reticular cells proliferated prominently and the macrophages with tingible bodies scattered frequently.
\end{abstract}

\section{INTRODUCTION}

Immunotherapy is now a generally acceptable approach to the treatment of human malignant diseases. Among a variety of immunotherapeutic agents, Mycobacterium bovis strain BCG (BCG) is, at present, the most widely employed (Bast et al., 1974; Mastrangelo, Berd and Bellet, 1976); the mode of its anti-tumor

\footnotetext{
**Present address: Department of Pediatrics, Nippon Medical School, Sendagi 1-1-5, Bunkyo$\mathrm{ku}$, Tokyo 113.

徳永 徹・田口 悟・室橋豊穂(国立予防衛生研究所 結核部)

茅野文利（同病理部）
} 
action has also been studied most extensively (Bast et al., 1974; Bast and Bast, 1976; Zbar et al., 1976; Florentine et al., 1976; Tokunaga et al., 1978). Among various methods for administration of BCG to cancer patients, "local immunotherapy (Zbar et al., 1976)" or "adjuvant contact therapy (Baldwin, Hopper and Pimm, 1976)", in which BCG is introduced into the area of the tumor, has been reported to be the most efficious. Repeated intratumor injections or frequent scarifications with large doses of BCG, however, sometimes caused hazardous local or systemic side-effects in cancer patients whose immunologic states are usually depressed more or less (Bast et al., 1974; Mastrangelo et al., 1976). On the other hand, BCG administered orally showed no complication, even by weekly administrations of large doses for periods of years (Lewis et al., 1976). Beneficial effects of oral BCG for cancer patients have been reported in a few cases (Falk et al., 1976a, b; MacDonald, Norvell and Bodurtha, 1976; Fujii et al., 1978; Murohashi et al., 1978), although definite conclusions can not be drawn from the randomized therapeutic trials, at present. In view of its low toxicity and ease in administration, the anti-tumor effects of oral BCG deserve experimental re-examinations. There has been, however, no report on therapeutic trials of animal tumors by this hazardless route of BCG administration, except a report of Baldwin, Hopper and Pimm (1975) stating that oral BCG inhibits neither the intraperitoneal or pulmonary growth of a transplanted rat sarcoma nor the development of post-surgical pulmonary reaction from a transplanted epithelioma. Under these circumstances, we examined the therapeutic efficacy of oral BCG against various, allogeneic or syngeneic tumors of mice and guinea pigs.

\section{Materials ANd Methods}

Animals: C57BL/6J mice were purchased from Funabashi Animal Farm (Funabashi, Chiba) and ddY and CDF1 mice from Shizuoka Experimental Animal Cooperative (Hamamatsu, Shizuoka). All the mice were female, 6-8 weeks of age, and fed with commercial pellets. Inbred strain-2 guinea pigs were purchased from Nippon Institute for Biological Science (Tachikawa, Tokyo) and Hartley/F guinea pigs from Funabashi Animal Farm. All the guinea pigs were male, 350$400 \mathrm{~g}$ in weight, and fed with commercial pellets.

Tumors: B16 melanoma was given by T. Matsumoto (Takeda Chemical Industries, Ltd., Osaka) in 1976, and has been maintained in syngeneic female C57BL/6 J mice. IMC ascitic carcinoma was given by M. Ishizuka (Inst. Microbiol. Chem., Tokyo) in 1977 and has been maintained in syngeneic female CDF1 mice. Ehrlich ascites tumor was given by T. Tanaka (National Cancer Center Inst., Tokyo) in 1973 and has been maintained in female ddY mice. Line-10 hepatocarcinoma in strain-2 guinea pig was given by B. Zbar (National Cancer Inst., N.I.H., Bethesda, MD, U.S.A.) in 1975 and has been maintained in young, male strain-2 guinea pigs. H10 liposarcoma and H9A fibrosarcoma, induced in female Hartley/F guinea pigs with methylcholanthrene (Kataoka and Tokunaga, 1975) have been maintained in female Hartley/F. 
Preparation of tumor cell suspension: Cell suspensions of solid tumors, B16 melanoma, H9A fibrosarcoma and H10 liposarcoma, were prepared by the method described before (Tokunaga et al., 1973). Briefly, a solid tumor was removed from the host, minced finely, suspended in Hanks' balanced salt solution (HBSS), and then digested by both pronase and DNase. The tumor cells were washed twice and resuspended in HBSS. Ehrlich ascites tumor cells, obtained from mice inoculated with $10^{6}$ Ehrlich cells 12 days before, were washed twice, and suspended in cold HBSS. Suspension of line-10 ascitic tumor cells was prepared according to Rapp et al. (1968). Viable cells in all of the tumor cell suspensions were counted by the trypan blue exclusion technique, and adjusted with by HBSS to adequate viable cell concentrations.

$B C G$ : Lyophilized BCG manufactured by Japan BCG Laboratory (Tokyo) was suspended in physiologic saline, washed once and adjusted to an appropriate concentration. Eighty milligrams of the lyophilized vaccine contained approximately $2 \times 10^{9}$ colony-forming units (CFU) of BCG. In an experiment, freshly cultured BCG was prepared by the method of Mackaness et al. (1973). Heatkilled BCG was prepared by heating this BCG at $100 \mathrm{C}$ for $5 \mathrm{~min}$.

Administration of $B C G$ : Mice or guinea pigs were given single or repeated intraoesophageal gastric instillation with BCG by careful..gavage, or single or repeated sc injections with BCG at the contralateral site to id tumors. One oral dose of BCG was $5 \mathrm{mg}$ for the mouse and $80 \mathrm{mg}$ for the guinea pig, and one sc dose was $0.5 \mathrm{mg}$ for the mouse and $8 \mathrm{mg}$ for the guinea pig. The first administration of BCG was carried out on the next day of tumor cell inoculation. Subsequent schedules of BCG administration are described in the text.

Assessment of tumor growth: Tumor cells were inoculated intradermally or subcutaneously. The number of tumor cells inoculated is indicated in the text. Palpable growth of tumors was examined at intervals and the average of two perpendicular diameters recorded. Because of wide variability within experimental groups, the growth of individual tumors was plotted.

Delayed-type-hypersensitivity $(D T H)$ reaction to $P P D$ : Mice were injected intradermally with $500 \mathrm{TU}$ PPD in $0.05 \mathrm{ml}$ of saline into a hind footpad. Saline was injected into the other hind footpad as a control. The footpad swelling was measured with a dial thickness gauge (Peacock, Ozaki Co. Ltd., Tokyo) $24 \mathrm{hr}$ after injection. The difference in the thickness expressed in $0.1 \mathrm{~mm}$ between the two hind footpads was designated as the footpad reaction (FPR). In guinea pigs, skin reactions (redness) produced by id injection with 25 TU of PPD were read at $24 \mathrm{hr}$ and the average of two perpendicular diameters was recorded in millimeters. Skin reactions measuring more than $10 \mathrm{~mm}$ were considered to be positive.

Viable counts of BCG in organs: Animals were sacrificed and autopspy was performed. The spleens and livers were weighed and a part of each organ was ground in a Teflon homogenizer. One-tenth milliliter portions of its serial dilutions were inoculated onto slants of Ogawa's egg medium. Mesenteric nodes and three of the large Peyer's patches were removed aseptically, trimmed from 
the surrounding mucosal tissue, and homogenized in sterile cold saline. Onetenth milliliter portions of each suspension were inoculated onto slants of Ogawa's egg medium.

Histology: Peyer's patches from the small intestines of $\mathrm{C} 57 \mathrm{BL} / 6 \mathrm{~J}$ mice and Hartley/F guinea pigs with or without oral administration of BCG were sectioned and stained with hematoxylin and eosin.

\section{RESULTS}

\section{Effects on IMC Carcinoma in Mice}

Sixteen CDF1 mice were inoculated intradermally with $1 \times 10^{6}$ IMC carcinoma cells. Ten of the mice were given oral BCG weekly, and the other six remained untreated. Tumor growth in these two groups is shown in Fig. 1. No tumor regressed in either group, but growth of some tumors in the oral BCG group (Fig. 1B) retarded, comparing with that in the control group (Fig. 1A). The mean diameters of the tumors were $24.35 \pm 5.66 \mathrm{~mm}$ and $33.0 \pm 3.62 \mathrm{~mm}$ in the BCG group and the control group, respectively, 35 days after the tumor cell inoculation. The difference in the tumor size between the two groups was statistically significant with $\mathrm{p}$ values of 0.01 on the 10 th day, 0.02 on the 15 th and 20 days, 0.01 on the 25 th, 30 th and 35 th days, and 0.05 on the 40 th day of the experiment.

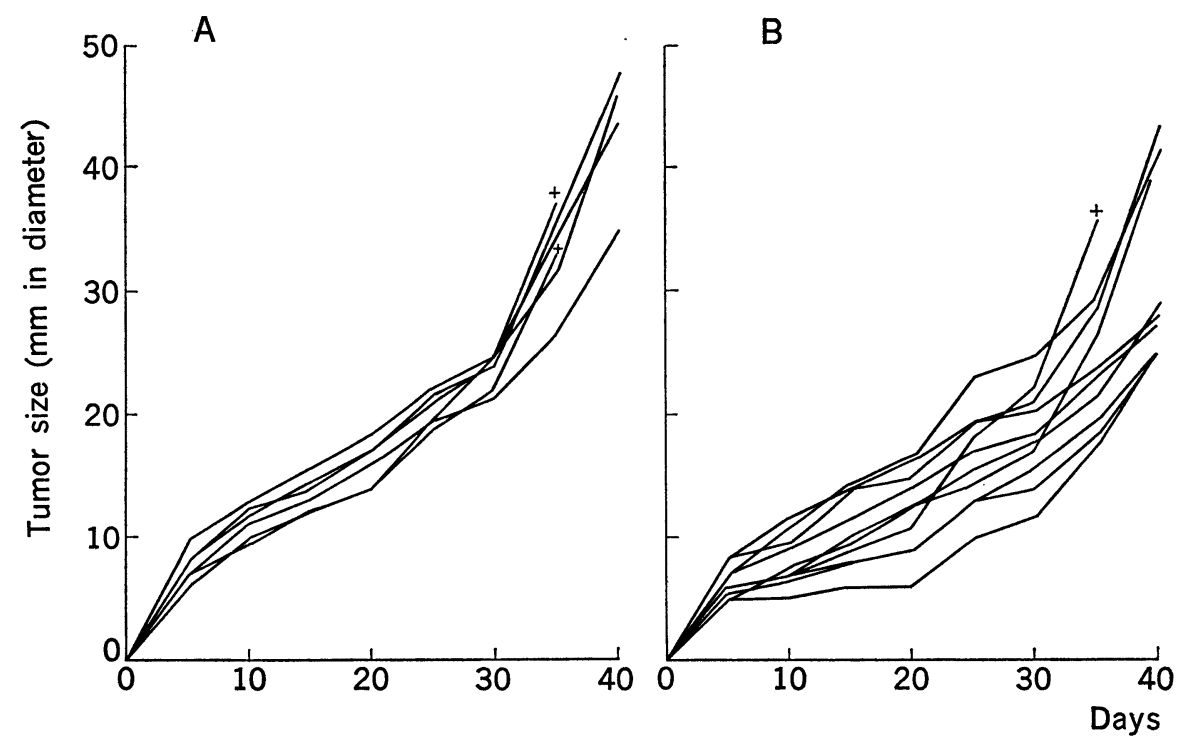

Fig.1. Effects of oral BCG on IMC carcinoma of CDF1 mice. (A) indicates tumor growth in nontreated control mice, and (B) shows tumor growth in mice given oral BCG weekly. 


\section{Effects on Ehrlich Solid Tumor in Mice}

Fourty ddY mice were injected intradermally with $1 \times 10^{7}$ Ehrlich tumor cells, and divided into five groups. The 1st and the 2nd groups were given oral BCG once and twice a week, respectively, until all animals died. The 3rd and the 4th groups were given sc injection with BCG once and once a week for 5 weeks, respectively. The last group remained as a nontreated control. All the mice of all groups developed tumors and died; no significant difference was observed among the groups.

A similar experiment was repeated with a reduced number of tumor cells for inoculation. Thirty-six mice were inoculated intradermally with $1 \times 10^{6}$ tumor cells; 15 of them were given BCG orally once a week, other 12 were injected subcutaneously BCG once, and the other nine remained as nontreated controls. The tumor growth was measured twice a week and the results obtained are shown in Fig. 2. In the control group (Fig. 2A), all tumors grew progressively during the first 2 weeks, and then two of the nine regressed spontaneously. Tumor regression was observed in four of the 12 mice injected BCG subcutaneously (Fig. 2B) and in 12 of the 15 mice given BCG orally (Fig. 2C).

Mice were inoculated intradermally with $2 \times 10^{6}$ Ehrlich tumor cells and then divided into three groups (11 mice each). Group A was a nontreated control,

A
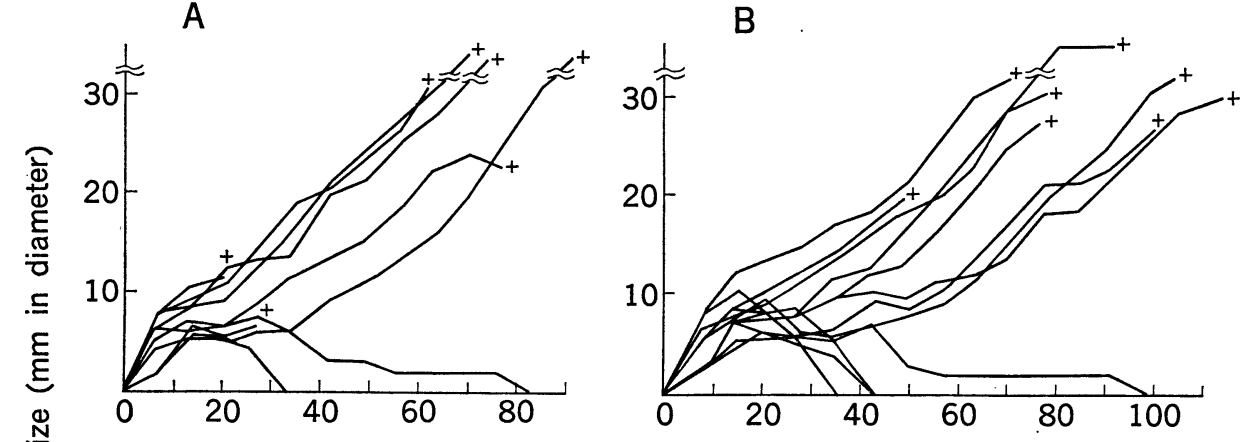

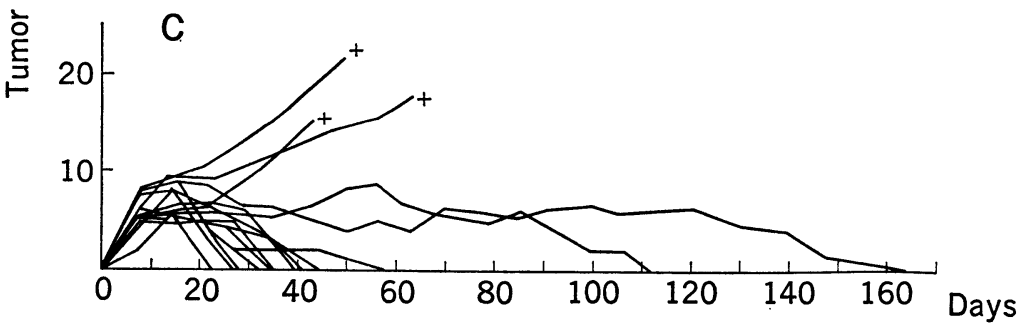

Fig. 2. Effects of oral BCG on Ehrlich solid tumors of ddY mice. Tumor cells $\left(1 \times 10^{8}\right)$ were inoculated intradermally. (A) indicates tumor growth in nontreated control mice, (B) indicates that in mice given single sc injection with BCG, and $(C)$ shows that in mice given oral BCG once a week. 
Group B was given oral BCG once a week, and Group C was given oral BCG twice a week. Regression of established tumors was observed in one mouse in Group A, three in Group B and two in Group C. The mean survival time of the dead mice was 60.5 days in Group A, 73.4 days in Group B, and 43.4 days in Group C. All of the six mice whose tumors regressed were challenged intradermally with $1 \times 10^{5}$ Ehrlich cells 3 months after the beginning of the experiment. All the mice rejected the challenged tumor cells.

Such an experiment was repeated with freshly cultivated BCG and its heatkilled sample instead of lyophilized BCG. Sixty mice were divided into six groups (10 mice each) and inoculated intradermally with $2 \times 10^{5}$ (Group A, B and C) or $5 \times 10^{5}$ (Group D, E and F) of Ehrlich cells. Group A and D were nontreated controls. Group B and E were given weekly heat-killed BCG $\left(5.3 \times 10^{7}\right.$ per mouse) orally. Group $\mathrm{C}$ and $\mathrm{F}$ were given weekly oral administration of the same amount of viable BCG. The results obtained with Groups A, B and $\mathrm{C}$ are shown in Fig. 3. Although data are not shown here, tumor regression was observed in one of Group D, three of Group E and one of Group F.

Mice were inoculated intradermally with $2 \times 10^{5}$ Ehrlich tumor cells. Group A (nine mice) served as a nontreated control. Group B (nine mice) and

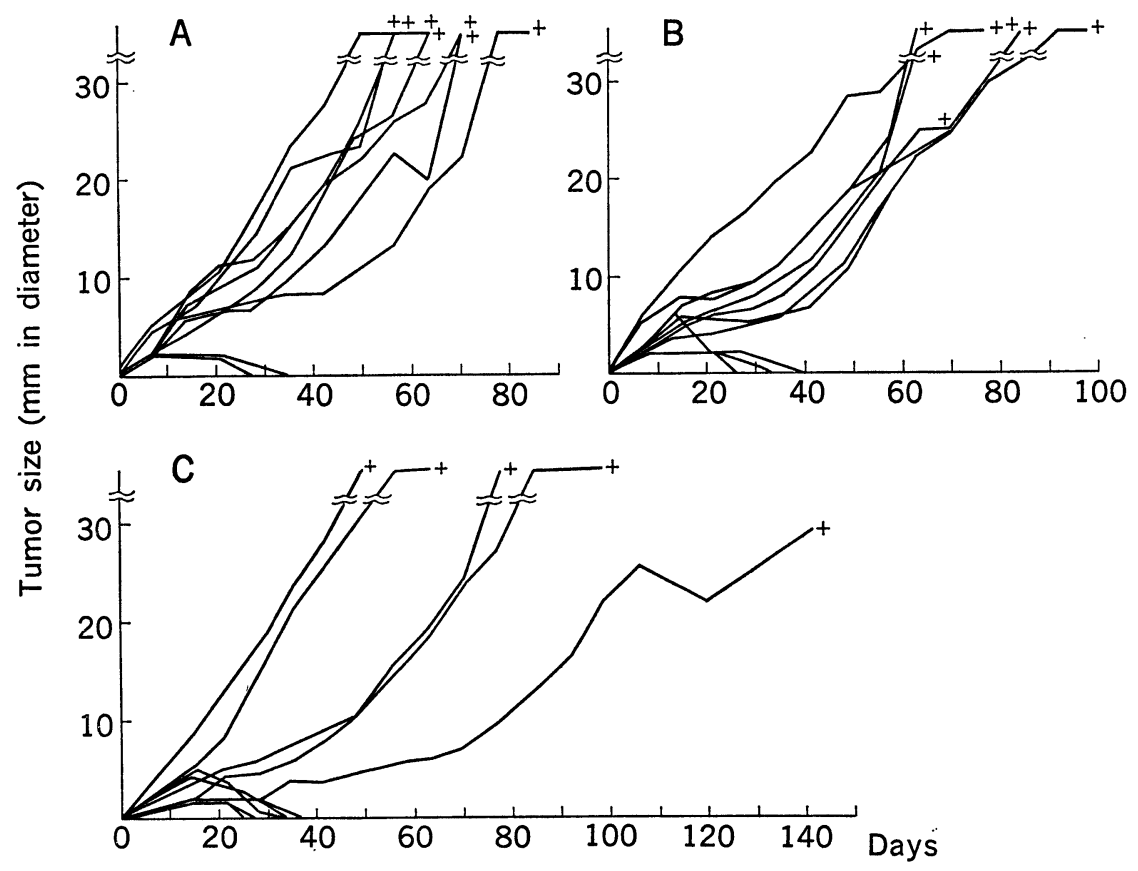

Fig. 3. Effects of oral BCG on Ehrlich solid tumors of ddY mice. Tumor cells $\left(2 \times 10^{5}\right)$ were inoculated intradermally. (A) indicates tumor growth in nontreated control mice, (B) indicates that in those given heat-killed BCG orally once a week, and (C) shows that in those given oral BCG weekly. 
TABLE I

Regression rates of Ehrlich solid tumors in ddY mice

\begin{tabular}{|c|c|c|c|c|c|c|c|}
\hline \multirow[b]{2}{*}{ Exp. } & \multirow{2}{*}{$\begin{array}{l}\text { Number of } \\
\text { tumor cells } \\
\text { inoculated }\end{array}$} & \multirow{2}{*}{$\begin{array}{l}\text { Nontreated } \\
\text { control }\end{array}$} & \multicolumn{2}{|c|}{ Oral live-BCG } & \multirow{2}{*}{$\frac{\text { Oral killed-BCG }}{\text { once a week }}$} & \multicolumn{2}{|c|}{ S.c. live-BCG } \\
\hline & & & $\begin{array}{c}\text { once } \\
\text { a week }\end{array}$ & $\begin{array}{c}\text { twice } \\
\text { a week }\end{array}$ & & once & 5 times \\
\hline 1 & $1 \times 10^{7}$ & $0 / 10^{a}$ & $0 / 10$ & $0 / 10$ & N.D. & $0 / 10$ & $0 / 10$ \\
\hline 2 & $1 \times 10^{6}$ & $2 / 9$ & $12 / 15$ & N.D. $b$ & N.D. & $4 / 12$ & N.D. \\
\hline 3 & $2 \times 10^{6}$ & $1 / 11$ & $3 / 11$ & $2 / 11$ & N.D. & N.D. & N.D. \\
\hline \multirow[t]{2}{*}{4} & $2 \times 10^{5}$ & $2 / 10$ & $5 / 10$ & N.D. & $3 / 10$ & N.D. & N.D. \\
\hline & $5 \times 10^{5}$ & $1 / 10$ & $3 / 10$ & N.D. & $1 / 10$ & N.D. & N.D. \\
\hline 5 & $2 \times 10^{5}$ & $3 / 9$ & $6 / 9$ & $5 / 9$ & N.D. & $3 / 9$ & $3 / 10$ \\
\hline Total $^{c}$ & & $\begin{array}{c}9 / 59 \\
(15.5 \%)\end{array}$ & $\begin{array}{c}30 / 65 \\
(46.1 \%)\end{array}$ & $\begin{array}{c}7 / 30 \\
(23.3 \%)\end{array}$ & $\begin{array}{c}4 / 20 \\
(20.0 \%)\end{array}$ & $\begin{array}{c}8 / 31 \\
(25.8 \%)\end{array}$ & $\begin{array}{c}3 / 20 \\
(15.0 \%)\end{array}$ \\
\hline
\end{tabular}

$a$ : Values indicate the ratio of the number of mice whose tumors regressed to the number of mice inoculated with tumor cells.

$b$ : N.D.: Not done.

$c$ : See the text.

Group C (10 mice) were given sc BCG once and once a week for 5 weeks, respectively. Group D (nine mice) and Group E (nine mice) were given oral BCG once a week and twice a week, respectively. Tumor regression was observed in three each of Groups A, B and C, six of Group D, and five of Group E. One each of Groups B, C and E survived more than 110 days of the whole experimental period, while all the control mice died within 95 days.

The regression rates in the above five experiments are summarized in Table I. Since the experimental conditions were not exactly the same from one to another, calculation of the tumor regression rate by simply averaging the results of the five experiments would be incorrect. Such averages are, however, shown in the lowest row of Table I. These experiments may suggest that the highest rate of tumor regression is found in the mice given oral BCG once a week. The mice given oral BCG twice a week or single sc BCG do not show apparently higher regression rates than do nontreated controls. Neither oral administration of heatkilled BCG nor repeated sc injections of BCG showed any significant effect.

\section{Effects on Melanoma B16 in Mice}

Twenty C57BL/6J mice were given intradermally with $4 \times 10^{6}$ melanoma cells and then divided into two groups. Group A was nontreated control and Group B was given oral BCG once a week. As indicated in Fig. 4, all the mice died within 35 days; no significant difference in the survival rate or the tumor growth rate was observed between the two groups. 


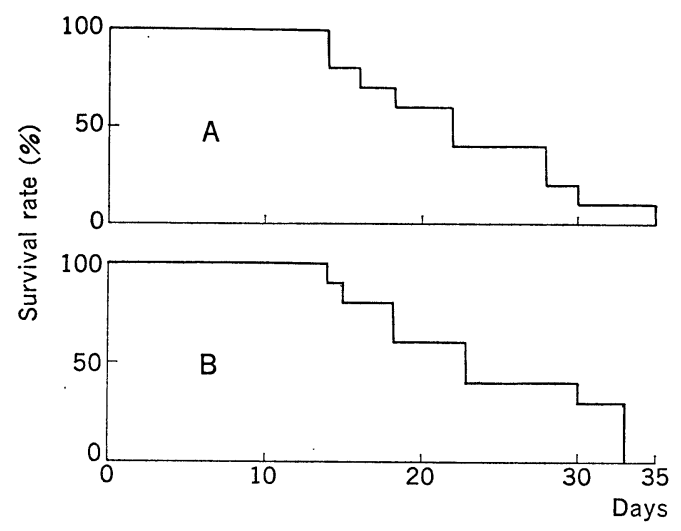

Fig. 4. Effects of oral BCG on B16 melanoma of C57BL/6J mice. (A) indicates survival rate of nontreated control mice, and (B) indicates that of mice given oral BCG once a week.

\section{Effects on Line-10 Tumor in Guinea Pigs}

Twenty strain-2 guinea pigs were given id injection of $1 \times 10^{5}$ line- 10 ascitic tumor cells and then divided into four groups (five each). Group A served as a nontreated control. Group B was given oral BCG once a week. Group C was given oral BCG 3 times a week for 2 weeks, and then once a week until the animals died. Group D was given a single sc BCG at the site contralateral to tumor cells. After a week of the tumor cell inoculation, tumors of about $10 \mathrm{~mm}$ in diameter were palpated and grew progressively in all animals. DTH to PPD was tested after 4 week, and positive DTH. reactions were observed only in Group D. After about three weeks, axillar metastatic tumors were palpated in all the animals of each group as shown in Fig. 5. No significant difference in the growth of primary and metastatic tumors or the survival time was observed among the groups.

\section{Effects on H10 Liposarcoma in Guinea Pigs}

Fourteen guinea pigs were inoculated subcutaneously with $2 \times 10^{7} \mathrm{H} 10$ cells and then divided into two groups (seven each). One group was given oral BCG once a week, and the other was nontreated. The results are shown in Fig. 6. All animals in the control group developed tumors and died within 63 days. On the other hand, two guinea pigs given oral BCG did not develop tumor at all. The remaining five developed tumors but three of the five tumors grew rather slowly.

The same experiments were repeated 3 times. Contrary to the first experiment, some of the tumor transplants were rejected by not only the animals given oral BCG but also by the nontreated controls. Throughout the four experiments, 49 guinea pigs in total were inoculated with $\mathrm{H} 10$ cells; 25 of them were given oral BCG once a week. Ten of the 25 animals $(40.0 \%)$ in the BCG groups and 


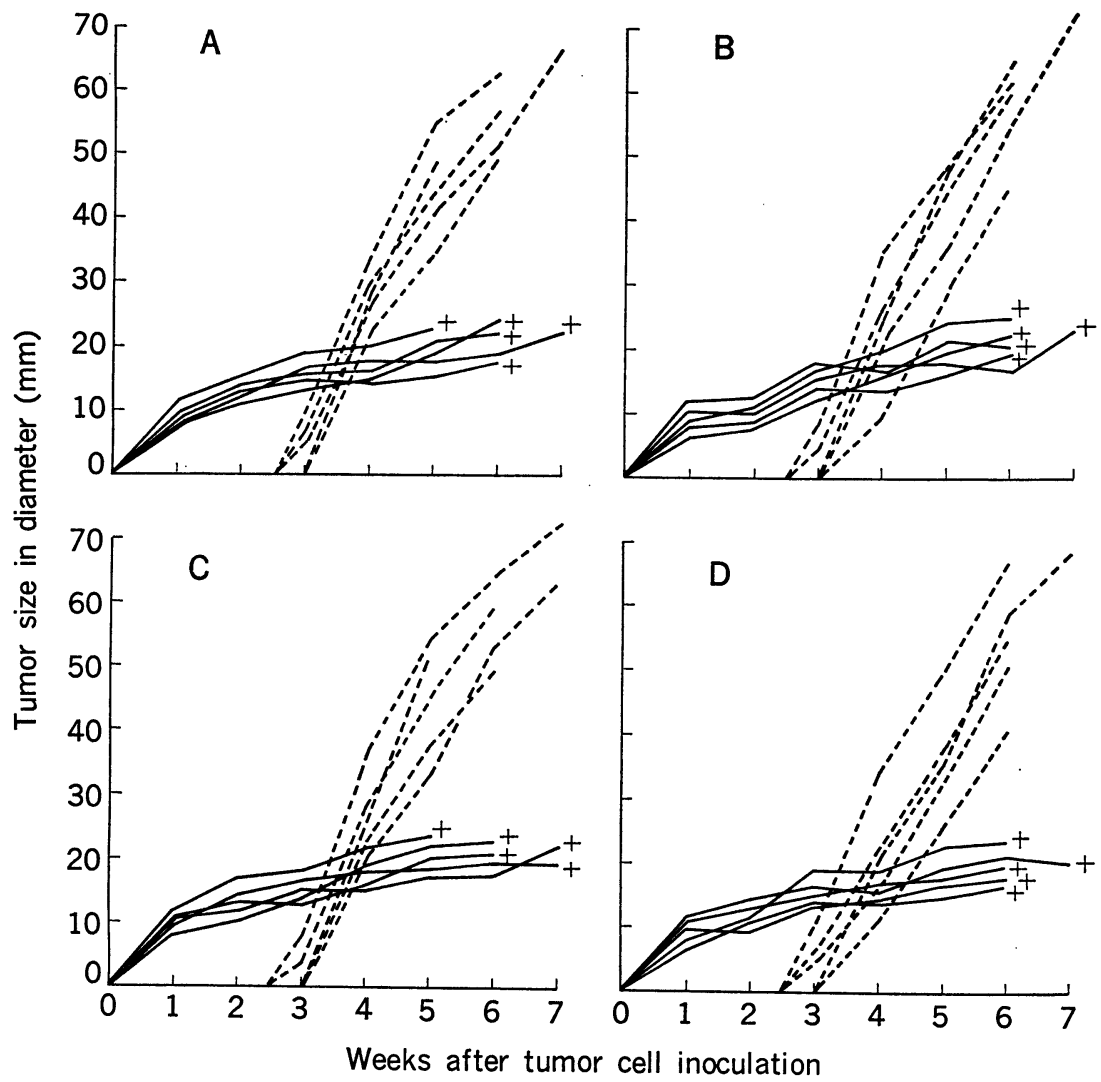

Fig. 5. Effects of oral BCG on line-10 carcinoma in strain-2 guinea pigs. (A) indicates tumor growth in nontreated control animals, (B) shows that in animals given oral BCG once a week, (C) shows that in animals given oral BCG weekly for the first 2 weeks and then once a week, and (D) indicates that in animals given a single sc BCG. Solid lines indicate growth of primary transplants and dotted lines indicate that of axillary metastases.

four of the 24 animals $(16.6 \%)$ in the control groups did not take tumors. All tumors, if appeared once, grew continuously and killed the hosts, but the survival periods of the BCG group seemed longer than those of the control group; animals without BCG administration died within 8 weeks except one that survived until the 9 th week, while four survived more than 10 weeks in the BCG group.

\section{Effects on H9 Fibrosarcoma in Guinea Pigs}

Ten guinea pigs were inoculated subcutaneously with $2 \times 10^{7}$ cells of $\mathrm{H} 9 \mathrm{~A}$ tumor. Six of the animals were given oral BCG once a week, and the other four remained nontreated. Results are shown in Fig. 7. All tumors grew progressively in the control group and killed the hosts, while they grew progressively during 


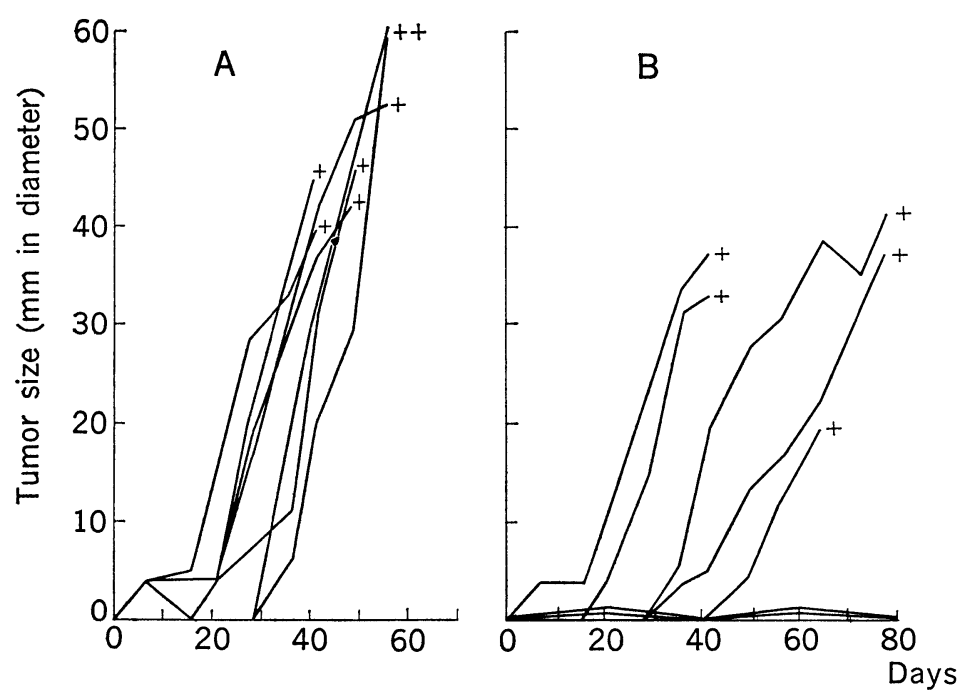

Fig. 6. Effects of oral BCG on $\mathrm{H} 10$ liposarcoma of Hartley/F guinea pigs. (A) indicates tumor growth in nontreated control guinea pigs, and (B) shows that in those given oral BCG weekly.

the first month in the BCG group. Two of the tumors developing in the latter group began to regress and disappeared finally; growth of the other one tumor retarded and the host survived more than 130 days, suggesting a prominent efficacy of oral BCG on this tumor. Unfortunately, this experiment could not be repeated, because we failed to maintain this tumor.

\section{$D T H$ and Organ Distribution of $C F U$ after Oral Administration of $B C G$}

Five Hartley/F guinea pigs were each given orally $80 \mathrm{mg}$ of BCG once a week for 11 weeks, and three guinea pigs were each given a single sc injection of $8 \mathrm{mg}$ of BCG. These animals were tested for DTH to $25 \mathrm{TU}$ of PPD at intervals. The results are shown in Fig. 8.

All animals given BCG by the sc route developed strong DTH within 10 days. On the other hand, skin reactions of the animals given oral BCG remained negative for 7 weeks after the first BCG administration; four of the five became positive in the 9 th week, but the other one still remained negative even 11 weeks after. On the 80th day, all the animals given oral BCG were sacrificed and CFU in the organs were determined. The results are shown in the row of Exp. 1 in Table II. Although CFU varied from one animal to another, it was apparent that relatively large numbers of CFU were detected in Peyer's patches and the mesenteric lymph nodes, but almost none in the spleens or the livers. The results were reproducible in a similar experiment repeated. 


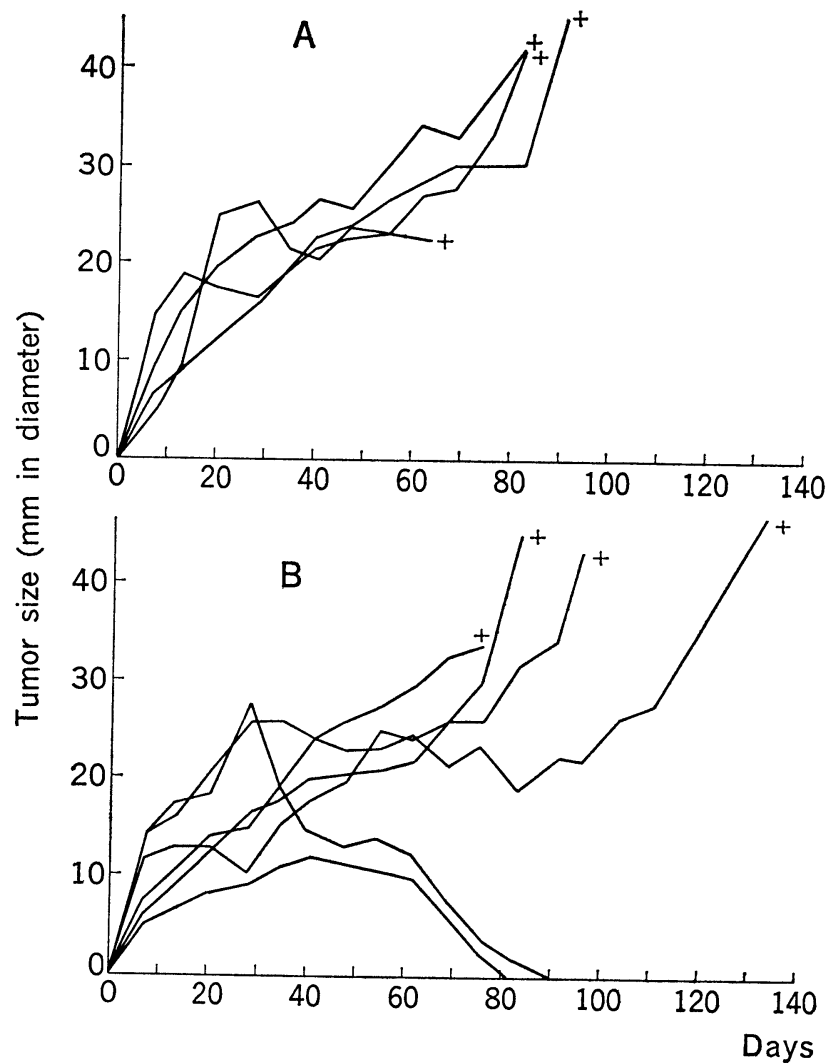

Fig. 7. Effects of oral BCG on H9A fibrosarcoma of Hartley/F guinea pigs. (A) indicates tumor growth in nontreated control guinea pigs, and (B) shows that in those given oral BCG weekly.

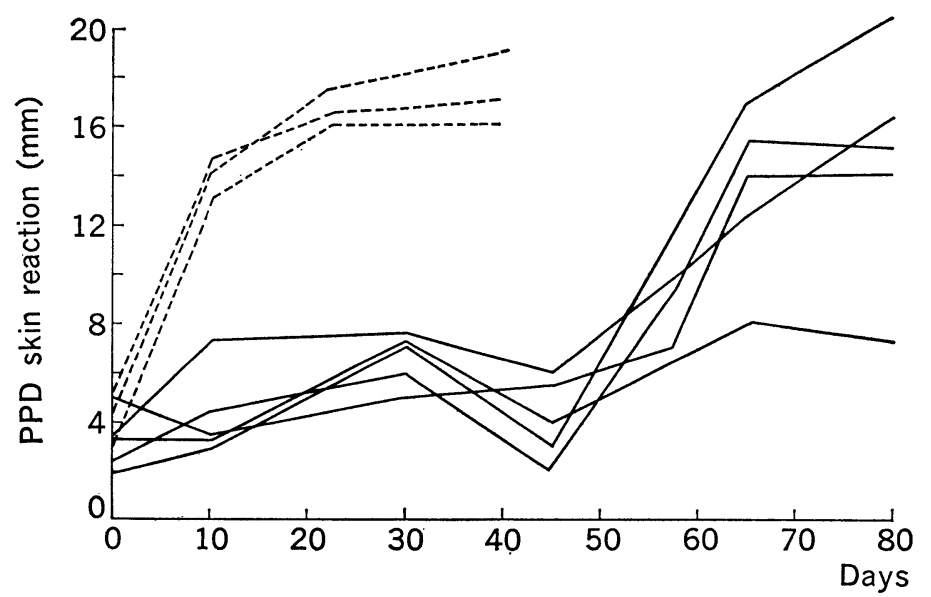

Fig. 8. Delayed-type skin reactions to PPD (25 TU) in guinea pigs given orally $80 \mathrm{mg}$ of BCG once a week (solid lines) or subcutaneously $8 \mathrm{mg}$ of BCG on day 0 (dotted lines). Each line expresses the diameter of redness $(\mathrm{mm})$ in individual animals. 
TABLE II

DTH to PPD in guinea pigs and mice after oral BCG administration and CFU de-

\begin{tabular}{ccccccc}
\hline Exp. & Animal & $\begin{array}{c}\text { Number } \\
\text { of } \\
\text { animals }\end{array}$ & $\begin{array}{l}\text { Schedule of BCG } \\
\text { administration }\end{array}$ & $\begin{array}{c}\mathrm{DTH}^{a} \\
(\mathrm{~mm} \pm \text { S.D. }\end{array}$ & Spleen & Liver \\
\hline I & $\begin{array}{l}\text { Guinea } \\
\text { pig }\end{array}$ & 5 & $\begin{array}{l}\text { Oral BCG weekly } \\
\text { for 11 weeks }\end{array}$ & $14.7 \pm 4.9$ & 0.3 & 0.2 \\
\hline \multirow{2}{*}{ II } & $\begin{array}{l}\text { Guinea } \\
\text { pig }\end{array}$ & 3 & $\begin{array}{l}\text { Oral BCG daily } \\
\text { for 4 days }\end{array}$ & $4.3 \pm 1.9$ & 0.1 & N.D.c \\
\cline { 6 - 7 } & 3 & S.c. BCG once & $14.0 \pm 1.7$ & 158.3 & N.D. \\
\hline \multirow{2}{*}{ III } & Mouse & 5 & $\begin{array}{l}\text { Oral BCG weekly } \\
\text { for 4 weeks }\end{array}$ & $1.20 \pm 0.35$ & 9.0 & 0.2 \\
\cline { 5 - 7 } & 5 & S.c. BCG once & $6.33 \pm 1.19$ & 676.3 & 230.5 \\
\hline
\end{tabular}

$a$ : DTH was measured on the 80th day after the first BCG in Exp. I, the 14th day in

$b$ : Animals were sacrificed on the next day of the DTH measurement. Average CFU in the eric nodes were expressed as average CFU from the individual whole nodes. CFU in vidual intestine.

$c$ : N.D.: Not done.

Next, three Hartley/F guinea pigs were given BCG orally once a day for successive 4 days, and, as a control, three guinea pigs were given sc BCG on the 1st day. These animals were tested for PPD skin reaction on the 14 th day, and sacrificed on the next day to count CFU in various organs. The results are shown in the row of Exp. II in Table II.

A similar experiment was performed in ddY mice. Five mice were given oral BCG 4 times weekly, and other five mice sc BCG once. These mice were tested for DTH to PPD one day after the 4th oral BCG administration, and sacrificed in 30 days after the first BCG. The results are shown in the row of Exp. III in Table II. DTH was positive in the mice given sc BCG, while negative in the mice given oral BCG. From the former mice relatively large numbers of CFU were detected in all of the organs tested. On the other hand, no CFU was detected in any organ of three of the five mice given BCG orally; relatively small numbers of CFU were detected in the other two mice.

\section{Histology of Peyer's Patches after Oral BCG}

C57BL/6J mice were given oral BCG once a week for 4 weeks and sacrificed a week after the first BCG. Hartley/F guinea pigs were given oral BCG daily for 10 days and sacrificed 2 weeks after the last BCG. Peyer's patches from the small intestines of these sacrificed animals were sectioned and stained for microscopic observations. Peyer's patches from normal mice and guinea pigs were taken as controls. Typical pictures of these preparations are shown in Fig. 9. Comparing with the normal Peyer's patches, remarkable enlargement of the germinal centers was observed in the mice and guinea pigs given oral BCG. Within those 
tected in various organs

$\begin{array}{rc}\text { Mesentric n. } & \text { Peyer's patch } \\ 158.3 & 606.7 \\ 0.1 & 373.3 \\ 0.1 & 0.1 \\ 38.0 & \text { N.D. } \\ 135.0 & \text { N.D. }\end{array}$

Exp. II and the 30th day in Exp. III. DTH of mice was expressed in $0.1 \mathrm{~mm}$ of FPR. spleen and the liver were expressed as CFU per $10 \mathrm{mg}$ of the organ. CFU in the mesentPeyer's patches were expressed as the average of CFU per three large patches of the indi-

enlarged germinal centers, proliferation of primitive reticular cells was prominent and many macrophages with tingible bodies were observed.

\section{Discussion}

As indicated in the text, the efficacy of oral BCG for animal tumors was variable depending on such experimental conditions used as tumor and animal systems, number of tumor cells inoculated, and frequency of BCG administration. Under certain conditions, oral BCG was effective on a syngeneic mouse carcinoma, IMC; the tumors did not regress by oral $\mathrm{BCG}$ but the growth was retarded significantly. On the other hand, oral BCG was ineffective on some syngeneic tumors, such as B16 mouse melanoma and line-10 guinea pig hepatocarcinoma; these tumors grew progressively and killed the hosts in spite of frequent oral BCG. For allogeneic Ehrlich solid tumors, the rates of tumor regression in the oral BCG groups were always higher than those in the control groups, when a relatively small number of tumor cells (between $2 \times 10^{6}$ and $2 \times 10^{5}$ per animal) was inoculated; when $1 \times 10^{\top}$ tumor cells were inoculated, no difference between the BCG and the control groups was observed. Oral BCG given once a week seemed more effective than that given twice a week or given subcutanously once or repeatedly (Table II). Oral administration of heat-killed BCG was ineffective. It is difficult, however, to draw a definite conclusion on the efficacy of oral BCG on Ehrlich tumor, because some tumors in the control groups regressed spontaneously.

Oral BCG seemed to give some advantageous effects on a guinea pig lipo- 

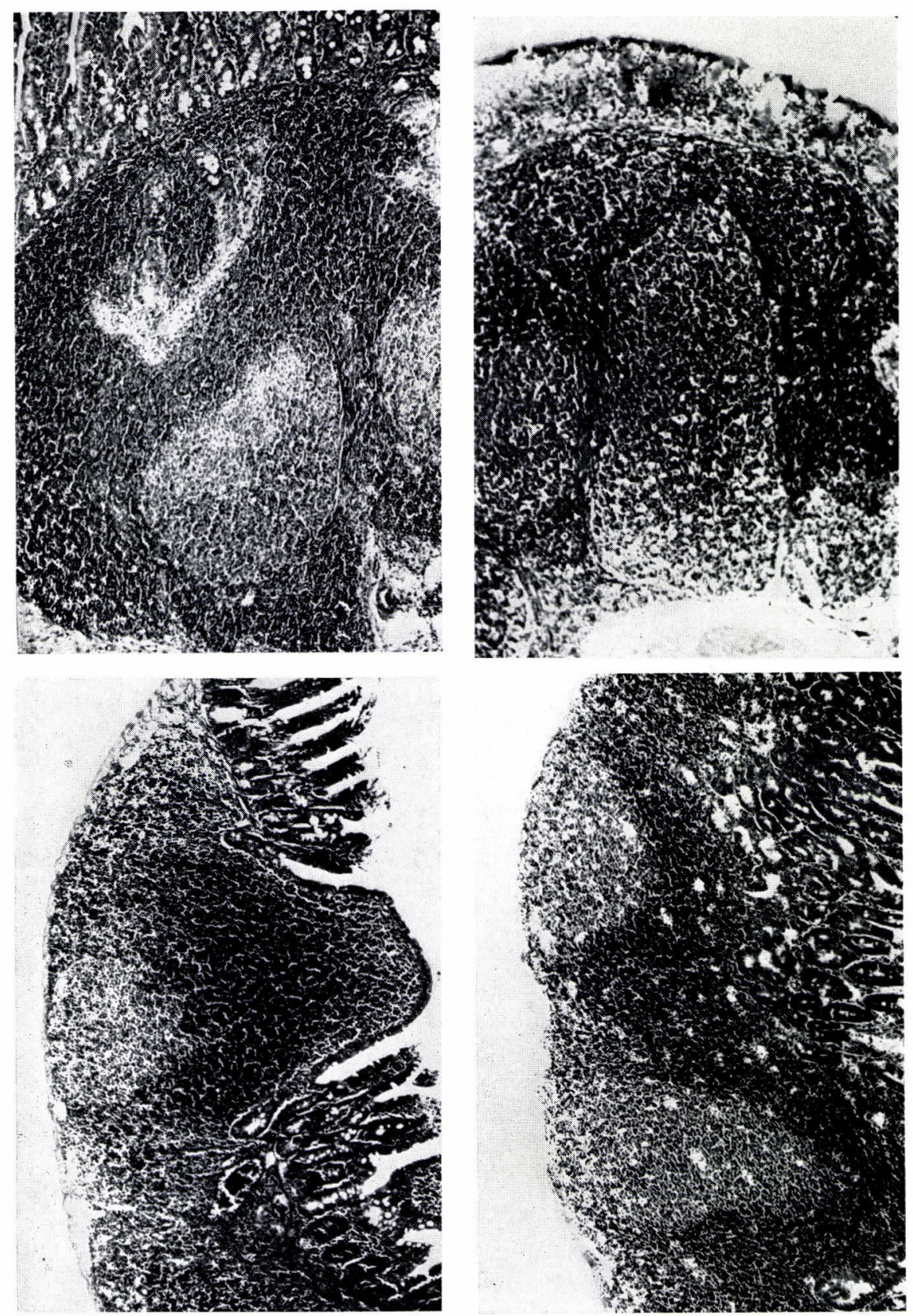

Fig. 9. Peyer's patches of mice and guinea pigs before and after oral BCG. (A) Peyer's patch of a control guinea pig. (B) Peyer's patch of a guinea pig given oral BCG. Note enlargement of the germinal center in which primitive reticular cells proliferate prominently and tingible macrophages scatter frequently. (C) Peyer's patch of a control mouse. (D) Peyer's patch of a mouse given oral BCG. Note enlargement of the germinal center as compared with that of the control mouse. 
sarcoma, H10. Throughout the four experiments, the rates of rejection of tumor transplants were always higher in the oral BCG groups $(40 \%$ in total) than those in the nontreated controls $(16.6 \%)$. The mean survival periods were also longer in the former groups. However, statistic analysis was impracticable because four of 24 control animals rejected tumor transplants. Whether the transplantable nature of the syngeneic tumor had changed through the in vivo maintaining or the inbred guinea-pig strain in a commercial colony was partially contaminated is under examination. The results obtained with guinea-pig fibrosarcoma H9A showed a prominent effect of oral BCG, although this experiment could not be repeated because of the failure in maintenance of $\mathrm{H} 9 \mathrm{~A}$.

Previously we experienced that single intratumor injections with BCG into all kinds of the solid tumors employed in this study showed much higher therapeutic effects (Tokunaga et al., 1978; Kataoka, Tokunaga and Murohashi, 1977). It may be concluded that oral BCG may show some inhibitory effects on certain tumors under certain experimental conditions, however the effects, even in the most efficious cases, are much lower than those of intratumor BCG. Since the oral route is known as the most hazardless for BCG administration, further studies on the effect of oral BCG, for instance, on possible restoration of the depressed-immune state in tumor-bearing animals and possible inhibition spontaneously-occurring, slow-growing tumors, are required.

The mechanism of the anti-tumor effect of oral BCG is still obscure, while that involved in "local" BCG therapy has been clarified relatively well (Bast et al., 1974, 1976; Zbar et al., 1976; Florentin et al., 1976; Tokunaga et al., 1978). In agreement with many reports, the present data showed that DTH to PPD could be induced by repeated oral administration of live BCG, although it took much longer time until the establishment of DTH than did single sc inoculation of BCG. The present results indicated also that a significant portion of viable BCG given orally reached the small intestine and trapped by Peyer's patches; only a few BCG passed through the patches and reached the mesenteric nodes. Morphological observation showed that lymphocytes in Peyer's patches responded to BCG and proliferated vigorously. It is known that lymphocytes in the patches contain both $\mathrm{T}$ and B lymphocytes in mice (Müller-Shoop and Good, 1975; Kagnoff and Campbell, 1974) and guinea pigs (Levin, Rosenstreich and Reynolds, 1973). The $T$ cells in Peyer's patches contain both helper $T$ and DTH T cells, as the $T$ cells could be carrier-primed for helper function in the induction of an antihapten response by feeding antigen (Kagnoff, 1975), and Peyer's patch lymphocytes showed the highest in vitro proliferative responses to PPD after oral BCG, while other lymphoid tissues showed no or little response (Müller-Shoop et al., 1975). We repeated the latter experiment and confirmed their results (data are not shown). The attached photographs (Fig. 9) indicate also that macrophages, which are naturally defficient in Peyer's patches (Kagnoff et al., 1974), infiltrated the patches responding to oral BCG.

Immunological events following the lymphocyte proliferation and macrophage infiltration in Peyer's patches are unknown. Regarding the circulation 
of immunocompetent cells to and from Peyer's patches, it was reported that migration of both $\mathrm{B}$ and $\mathrm{T}$ lymphoblasts to the small intestine is normally restricted to those originating from the thoracic duct or the mesenteric lymph nodes, and that peripheral $\mathrm{T}$ blasts accumulate into the small intestine if it is infected with parasites (Rose, Parrott and Bruce, 1976). On the other hand, based on the fact that the majority of large lymphocytes originated from the intestinal lymphoid tissues "homed" in the intestinal mucosa, an entero-enteric lymphocyte circulation was postulated (Müller-Shoop et al., 1975). Our data showing that frequent oral BCG did not easily convert PPD skin reaction, while lymphocytes in Peyer's patches responded well to PPD may support their postulation. If the intestinal immune responses are only a local phenomenon, a much smaller number of viable BCG provided more continuously into various internal organs, comparing with the case of sc BCG, might have an important meaning for tumor growth inhibition, although the concept of entero-enteric circulation needs to be substantiated by further studies.

It was reported that oral administration of yeast enhanced resistance to chronic infection with Brucella by means of in vivo stimulation of phagocytosis (Sinai et al., 1974) and that oral administration of viable Salmonella, but not heatinactivated cells, prevented growth of virulent Salmonella injected intravenously (Germanier, 1972). Recently, Murohashi et al. (1978) showed that oral BCG protected guinea pigs from infection with virulent tubercle bacilli. These indicate that orally administered microorganisms enhance both specific and non-specific resistance against microbial infection. The activation of the reticuloendotherial system may result also in removing possible immunosuppressive factors from the circulation of tumor-bearing animals. Polyclonal proliferation of $T$ cells accompanied with proliferation of BCG-sensitized $T$ lymphocytes in lymphoid organs might contribute to tumor suppression. In view of the presence of a common antigen between BCG and tumor cells (Minden, 1976; Lewis et al., 1976) suggested a possibility that oral BCG might produce tolerance to the crossreactive melanoma cytoplasmic antigens, thus allowing a more reactive antimembrane immune response. Further investigations on the specific and nonspecific host responses to oral BCG, including these possibilities, are required.

\section{AcKNOWLedGEMENTS}

The authors wish to thank Miss Mariko Takegawa for her technical assistance.

This work was supported in part by Grants-in-Aid for Cancer Research from the Ministry of Public Health and Welfare and from the Ministry of Education, Science and Culture, Japan.

\section{REFERENCES}

Baldwin, R. W., Hopper, D. G. ANd Pimm, M. V. (1975): Influence of orally administered BCG on growth of transplantable rat tumors. Brit. J. Cancer, 31, 124-128.

Baldwin, R. E., Hopper, D. G. ANd Pimm, M. V. (1976): Bacillus Calmette-Guerin contact immunotherapy of local and metastatic deposits of rat tumors. Ann. N. Y. Acad. Sci., 27, 124-134. 
Bast, R. C., JR., Zbar, B., Borsos, T. and Rapp, H. J. (1974): BCG and cancer. New Engl. J. Med., 290, 1413-1420.

BAST, R. C. AND BAST, B. S. (1976): Critical review of previously reported animal studies of tumor immunotherapy with nonspecific immunostimulants. Ann. N. Y. Acad. Sci., 277, 60-92.

Falk, R. E., Macgregor, A. B., Landi, S. L., Ambus, U. and Langer, B. (1976a): Immunostimulation with intraperitoneally administered Bacille Calmette Guerin for advanced malignant tumors of the gastrointestinal tract. Surg. Gynecol. Obst., 142, 363-368.

Falk, R. E., Macgregor, A. B., Ambus, U., Landi, S., Langer, B. ANd Miller, A. B. (1976b): The use of adjuvant therapy with BCG combined with chemotherapy in the treatment of gastrointestinal cancer. p. 217-225. In G. Laourex, R. Turcotte and Portelance [eds.], BCG in cancer immunotherapy, Grune \& Stratton, New York, San Francisco, London.

Florentin, I., Huchet, R., Bruley-Rsset, M., Halle-Pannenko, O. And Mathe, G. (1976): Studies on the mechanisms of action of BCG. Cancer Immunol. Immunother., 1, 31-39.

FujiI, G., Eriguchi, M., Miyamoto, Y., Mikamo, S., Murakami, G., Samaru, Y. and Sekiguchi, M. (1978): Oral administration of BCG in the treatment of gastrointestinal cancer. SaishinIgaku, 33, 1567-1573 (in Japanese).

Germainier, R. (1972): Immunity in experimental Salmonellosis. III. Comparative immunization with viable and heat-inactivated cells of Salmonella typhimurium. Infec. Immun., 5, 792-797.

Kagnoff, M. F. ANd Campbell, S. (1974): Functional characteristics of Peyer's patch lymphoid cells. J. Exptl. Med., 139, 398-406.

Kagnoff, M. F. (1975): Functional characteristics of Peyer's patch cells. III. Carrier priming of $\mathrm{T}$ cells by antigen feeding. J. Exptl. Med., 142, 1425-1435.

Kataoka, T. And Tokunaga, T. (1976): Transplantable sarcomas induced by 3-methylcholanthrene in inbred guinea pigs of JY-1 and Hartley/F strains. Gann, 67, 25-31.

Kataoka, T., Tokunaga, T. And Murohashi, T. (1977): Responses of tumors induced in inbred guinea pigs strain JY-1 and strain Hartley/F to BCG. J. Natl. Cancer Inst., 58, 803-808.

Levin, D. M., Rosenstreich, D. L. AND ReYnolds, H. Y. (1973): Immunologic responses in the gastrointestinal tract of the guinea pig. I. Characterization of Peyer's patch cells. J. Immunol., $111,980-983$.

Lewis, M. G., Jerry, L. M., Rowden, T. M., Phillips, T. M., Shibata, H. and Capek, A. (1976): Some effects of oral administration of BCG on immune responses in cancer patients. p. 339358. In G. Lamourex, R. Turcotte and V, Portelance [eds.] BCG in cancer immunotherapy, Grune \& Stratton, New York, San Francisco, London.

Macdonald, A. S., Norvell, S. T. ANd Bodurtha, A. I. (1976): Effects of oral BCG in solid tumors. p. 217-225. In G. Lamourex, R. Turcotte and V. Portelance [eds.], BCG in cancer immunotherapy, Grune \& Stratton, New York, San Francisco, London.

Mackaness, G. B., Auclair, D. J. and Lagrange, P. H. (1973): Immunopotentiation with BCG. I. Immune response to different strain and preparations. J. Natl. Cancer Inst., 51, 1655-1667.

Mastrangelo, M. J., Berd, D. ANd Bellet, R. E. (1976): Critical review of previously reported clinical trials of cancer immunotherapy with nonspecific immunostimulants. Ann. N. Y. Acad. Sci., 277, T4-122.

Müller-Shoop, J. W. AND Good, R. A. (1975): Functional studies of Peyer's patches: Evidence for their participation in intestinal immune responses. J. Immunol., 114, 1757-1760.

Minden, P. (1976): Shared antigens between animal and human tumors and microorganisms. p. 73-81. In G. Lamourex, R. Turcotte and V. Portelance [eds.], BCG in cancer immunotherapy, Grune \& Stratton, N. Y., San Francisco, London.

Murohashi, T., Horie, E., OHori, K. and Sato, H. (1978a): Effective treatment of a case with anaplastic lung cancer by the oral administration of BCG subsequent to the unsuccessful lobectomy. Saishin-Igaku, 389, 1663-1667 (in Japanese).

Murohashi, T., Miura, K., Takahashi, H. and Kinomoto, M. (1978b): Antituberculosis immunity of guinea pigs inoculated BCG orally. Kekkaku, 53, 465-470 (in Japanese).

Rapp, H. J., Churchill, W. H., Kronman, B., Rolley, R. T., Hammond, W. G. and Borosos, T. (1968): Antigenicity of a new diethylnitrosamine-induced transplantable guinea pig hepatoma; Pathology and formation of ascites variant. J. Natl. Cancer Inst., 41, 1-11.

Rose, M. L., Parrott, D. M. V. And Bruce, R. G. (1976): Migration of lymphoblasts to the small intestine. II. Divergent migration of mesenteric and peripheral immunoblasts to sites of in- 
flammation in the mouse. Cell. Immunol., 27, 36-46.

Sinai, Y., Kaplun, A., HaI, Y. ANd Halperin, B. (1974): Enhancement of resistance to infectious diseases by oral administration of Brewer's yeast. Infec. Immun., 9, 781-787.

Tokunaga, T., Kataoka, T., Nakamura, R. M., Yamamoto, S. and Murohashi, T. (1973): Tumor immunity induced by BCG-tumor cell mixtures in syngeneic mice. Japan. J. Med. Sci. Biol., $26,71-85$.

Tokunaga, T., Kataoka, T., Nakamura, R. M., Yamamoto, S. and Akagawa, K. (1978): Mode of anti-tumor action of BCG. Gann Monogr. Cancer Res., 21, 59-72.

Zbar, B., Ribi, E., Kelly, M., Granger, D., Evans, C. and Rapp, H. J. (1976): Immunologic approaches to the treatment of human cancer based on a guinea pig model. Cancer Immunol. Immunother., 1, 127-137. 